\title{
Preparation and characterization of antibacterial cobalt- exchanged natural zeolite/poly(vinyl alcohol) hydrogels
}

\author{
Güler Narin · Çisem Bulut Albayrak • \\ Semra Ülkü
}

Received: 22 July 2013/Accepted: 3 November 2013/Published online: 14 November 2013

(c) Springer Science+Business Media New York 2013

\begin{abstract}
In the present study, potential application of the local clinoptilolite-rich natural zeolite in formulation of antibacterial hydrogels was investigated. The zeolite powder exchanged with cobalt(II) ions was used in preparation of the zeolite/poly(vinyl alcohol) hydrogel films in different amounts. The films were physically crosslinked by the freezing-thawing method and characterized for their crystallinity, surface and cross sectional morphology, chemical composition, thermal behaviour, mechanical properties, swelling and dissolution behaviours, and antibacterial activities against a Gram-negative bacteria. The films with $0.48 \mathrm{wt} \%$ and higher cobalt-exchanged zeolite contents showed antibacterial activity. Addition of the zeolite powder in the formulations did not cause significant changes in the other properties of the films.
\end{abstract}

Keywords Natural zeolite - Hydrogel · Poly(vinyl alcohol) - Composite $\cdot$ Antibacterial .

Characterization

\section{Introduction}

Zeolites are porous crystalline aluminosilicates, composed of $\mathrm{TO} 4$ tetrahedra $(\mathrm{T}=\mathrm{Si}, \mathrm{Al})$ with $\mathrm{O}$ atoms connecting

G. Narin · Ç. B. Albayrak · S. Ülkü

Department of Chemical Engineering, Izmir Institute of

Technology, 35430 Urla, Izmir, Turkey

Present Address:

G. Narin $(\bowtie)$

Department of Chemical Engineering, Faculty of Engineering,

Usak University, 64200 Usak, Turkey

e-mail: guler.narin@usak.edu.tr neighbouring tetrahedra. Incorporation of aluminium atom instead of silica in the framework makes the framework negatively charged and requires to be balanced by extraframework cations such as $\mathrm{Na}^{+}, \mathrm{K}^{+}, \mathrm{Ca}^{2+}$, and $\mathrm{Mg}^{2+}$. Zeolites can be used as effective antibacterial agents when these extraframework cations are exchanged with metal ions having antibacterial activity.

Among antibacterial metals (silver, copper, zinc, mercury, tin, lead, bismuth, cadmium, chromium, cobalt, and nickel), silver ion is the most attractive because of its strong activity, wide spectrum, and low human toxicity. Incorporation of silver ions in a carrier support such as zeolites is a cost-effective alternative than the direct use of silver compounds such as silver nitrate solution and silver plate [1]. Silver-exchanged zeolites exhibited antibacterial activity against different bacterial strains and have been used in different formulations including household items, coatings for biomedical devices, wound dressing, and as tissue conditioner in dentistry [2-13].

Aggregation of the particles limits use of zeolites in powder form in various applications, especially those in aqueous medium. Incorporation of the zeolite powder into polymeric matrix makes zeolites practically more applicable. Furthermore, although incorporation of silver into molten polymers is a conventional approach to produce antimicrobial polymers, use of silver ion-loaded zeolites as antibacterial agent offers an advantage because silver ions are more effective than metallic silver atoms [14]. Moreover, since the diffusion rate of silver ions out of the silverzeolite/polymer composite is slower than that from the polymers obtained by direct loading of silver ions, the prolonged antimicrobial activity is expected [15]. Antibacterial properties were induced in polymer films by incorporation of $\mathrm{Ag}^{+}, \mathrm{Zn}^{2+}$ or $\mathrm{Cu}^{2+}$-exchanged zeolites. Inorganic/polymer composites prepared by incorporation 
of zeolites resulted in superior mechanical, thermal, and water permeability properties as compared to the polymeric films without zeolite [16-22]. On the other hand, the current European Union regulations aim to ban silver products from the medical industry due to the increased risk of toxicity and high price of silver-containing antimicrobial products [18].

Metals such as cobalt, nickel, copper, zinc, zirconium, molybdenium, and lead were found to have antibacterial properties against both Gram-positive and Gram-negative bacteria and proposed to be incorporated into antibacterial materials [23]. Zinc-exchanged natural zeolite was used as an active carrier for antibiotics and applied in the topical treatment of acne [24]. Silver, zinc, and copper-exchanged local clinoptilolite-rich natural zeolite from Gördes (Western Anatolia) was investigated for their antibacterial activity [25]. Cobalt complexes formed with mono and polydentate ligands are known for their antimicrobial or antiviral activity and have been used in medicine [26]. Cobalt-exchanged zeolite A pressed in discs using powder polymers was proposed as NOreleasing antibacterial and antithrombotic material [27].

Hydrogels are three-dimensional, hydrophilic, polymeric networks capable of imbibing large amounts of liquid. They can be formulated in a variety of physical forms, including slabs, microparticles, nanoparticles, coatings, and films. Due to their high water absorption capacity, biocompatibility and similarity to natural tissue, hydrogels can be used in various medical and pharmaceutical applications such as contact lenses, membranes for biosensors, artificial skin, and drug delivery [28]. Since they can maintain a moist environment around the wound required for increased reepithelization rate and for less scarring [29] and can be applied and removed without trauma to the wound, hydrogels have received considerable attention to be used in wound dressing formulations [30, 31]. Hydrogels can be either physically or chemically crosslinked. The physical crosslinking methods do not require use of chemical crosslinking agents many of which are toxic [32, 33]. One of the physical crosslinking methods is the freezing-thawing. Poly(vinyl alcohol) (PVA) is a highly hydrophilic, fiber/film-forming, non-toxic, and biocompatible synthetic polymer. PVA hydrogels prepared by the freezing-thawing method exhibited high swelling degree, high elasticity, biocompatibility, and non-toxicity [34-41].

Inorganic particles including clays, silica, hydroxyapatite, fumed silica, and zirconium phosphate nanoparticles are commonly used as reinforcing agents in order to improve the physical, thermal, and mechanical properties of the polymeric hydrogels [42-46].

The present study aims preparation and structural, mechanical, thermal and antibacterial characterization of the cobalt-exchanged natural zeolite/PVA hydrogels which can find an application as antibacterial hydrogels.

\section{Materials and methods}

\subsection{Preparation of the zeolite powders}

Zeolitic tuff from Gördes (Western Anatolia) supplied as a coarse powder was washed with hot deionized water twice and were dried in a static oven at $60{ }^{\circ} \mathrm{C}$ overnight and thereafter a successive grinding-dispersion-settling process, clinoptilolite-rich mineral in fine powder form was obtained. The grinding was performed on a planetary ball mill (PM-100, Retch). The size fractionation of the particles was carried out at the settling step based on the Stoke's law. This purified fine powder was converted to near homoionic sodium form by treating $1 \mathrm{~g}$ of the powder with $10 \mathrm{~mL}$ of $1 \mathrm{M}$ aqueous solution of sodium chloride ( $>99.5 \%$, SigmaUltra) in a constant temperature water bath at $80{ }^{\circ} \mathrm{C}$ for 9 days at $170 \mathrm{rpm}$. The $\mathrm{NaCl}$ solution was renewed each 3 days. Thereafter, the powder was washed with excess amount of deionized water to remove the chlorine and dried at $60{ }^{\circ} \mathrm{C}$ overnight. $1 \mathrm{~g}$ of this Nazeolite was treated with $100 \mathrm{~mL}$ of $0.01 \mathrm{M}$ aqueous solution of $\mathrm{Co}\left(\mathrm{NO}_{3}\right)_{2} \cdot 6 \mathrm{H}_{2} \mathrm{O}(>98 \%$, Sigma-Aldrich) in a constant temperature water bath at $60{ }^{\circ} \mathrm{C}$ for $24 \mathrm{~h}$ at $170 \mathrm{rpm}$. Subsequently, the powder was washed with excess amount of deionized water repeatedly to remove the excess cobalt salts and salts formed by the ion exchange process. The sample was dried at $60^{\circ} \mathrm{C}$ overnight and stored in closed polyethylene bottles under the room conditions. The zeolite powder obtained in this manner was labelled as "Co-zeolite".

The prepared zeolite powders were characterized for the particle size distribution, crystal size and morphology, crystallinity, elemental composition, and antibacterial activity. The particle size distribution analyses were performed using a particle size analyzer (Mastersizer 2000, Malvern Instruments). The crystal size and morphology were assessed by scanning electron microscopy (SEM) (XL-30S FEG SEM, Philips). The powders were deposited onto aluminum specimen stubs using double-side carbon tape prior to the analysis. X-Ray diffraction patterns of the zeolitic tuff and the powders were recorded on a powder diffractometer (X'Pert Pro, Philips) equipped with Ni-filtered $\mathrm{CuK} \alpha$ radiation source $(\lambda=0.1540560 \mathrm{~nm})$ over $2 \theta$ range of $5^{\circ}$ to $40^{\circ}$ at a $10.15 \mathrm{~s}$ measurement time per step, and a step size of $0.01671^{\circ}$. The X-ray source was operated at $40 \mathrm{~mA}$ and $45 \mathrm{kV}$. The database of the Joint Committee on Powder Diffraction Standards in the International Centre for Diffraction Data (JCPDS-ICDD, PDF-1 database) was used to interpret the crystalline mineral phases in the samples. Clinoptilolite contents of the zeolite samples were determined from the ratio of sum of intensities of the three most intense reflections of clinoptilolite phase of the samples to that of the reference clinoptilolite mineral 
(27031, Castle Creek, Idaho). Chemical compositions of the prepared zeolite powders were determined by an inductively coupled plasma atomic emission spectrometer with axial plasma (ICP-AES) (Liberty Series II, Varian). The powders were treated with an alkali borate fusion flux (anhydrous lithium tetraborate, Fluka; zeolite in $10 \mathrm{wt} \%$ ) and dissolved in $1.6 \mathrm{M} \mathrm{HNO}_{3}$ prior to the analysis.

Antibacterial activities of the zeolite powders were tested against the reference strains of Escherichia coli (NRLLB 3008) and Staphylococcus aureus (ATCC 29213) as representative for Gram-negative and Gram-positive bacteria, respectively, by the disc-diffusion method. The standardized bacteria cells were inoculated into nutrient broth and incubated at $37{ }^{\circ} \mathrm{C}$ overnight. Then, $19 \mathrm{~mL}$ of Mueller-Hinton agar was inoculated with $0.5 \mathrm{~mL}$ of the overnight-grown bacterial strains containing about $10^{8} \mathrm{cfu} /$ $\mathrm{mL}$ (cfu: colony forming units). The inoculated agar was then poured into petri dishes and allowed to set. Approximately $50 \mathrm{mg}$ of the zeolite powders were pressed into discs with $8 \mathrm{~mm}$ diameter and $0.7 \mathrm{~mm}$ thickness by a hydraulic press. After placing the discs on the agar, the agar plate was covered and incubated at $37{ }^{\circ} \mathrm{C}$ for $24 \mathrm{~h}$. Diameter of the clear growth inhibition zone around the each disc was measured with a micrometer and used as the measure of strength of the antibacterial activity. The antibacterial activity tests against each of the bacterium were performed in triplicate and the average growth inhibition zone diameters were reported.

\subsection{Preparation of the zeolite/PVA films}

Aqueous solutions of PVA were prepared by dissolving $1.5 \mathrm{~g}$ of PVA powder (average molecular weight of $31,000-50,000$, hydrolysis degree of $98-99 \%$, Aldrich) in $5 \mathrm{~mL}$ deionized water at $90{ }^{\circ} \mathrm{C}$ in a water bath under magnetic stirring. The Co-zeolite powder, which was dried at $37{ }^{\circ} \mathrm{C}$ until constant mass, was dispersed in $5 \mathrm{~mL}$ deionized water in an ultrasonic bath and added to the PVA solutions in 1,5 , and $10 \mathrm{wt} \%$ of their PVA contents corresponding to $0.48,2.40$, and $4.77 \mathrm{wt} \%$ zeolite in the dry films, respectively. Thereafter, the solutions were continuously stirred at $90{ }^{\circ} \mathrm{C}$ for $4 \mathrm{~h}$ and were cast in separate polyethylene petri dishes. The petri dishes were placed in an ultrasonic bath in order to eliminate the air bubbles observed in the solutions. The solutions were crosslinked by the freezing-thawing method by instantaneous freezing at $-80{ }^{\circ} \mathrm{C}$ for $16 \mathrm{~h}$ and then thawing at room temperature for $8 \mathrm{~h}$. After the six freezing-thawing cycles, circular specimens with $20 \mathrm{~mm}$ in diameter were cut off the films using a cork borer. The films were dried in a static oven at $37{ }^{\circ} \mathrm{C}$ until constant mass. The PVA films without the zeolite and with the Na-zeolite were prepared and tested as
Table 1 Compositions of the films

\begin{tabular}{lllll}
\hline Films & $\begin{array}{l}\text { Co-zeolite } \\
\text { content }(\mathrm{g})\end{array}$ & $\begin{array}{l}\text { Na-zeolite } \\
\text { content }(\mathrm{g})\end{array}$ & $\begin{array}{l}\text { Zeolite/ } \\
\text { PVA } \\
(\mathrm{wt} \%)\end{array}$ & $\begin{array}{l}\text { Zeolite content of } \\
\text { dry film }(\mathrm{wt} \%)^{\mathrm{a}}\end{array}$ \\
\hline 1 & 0.150 & - & 10 & 4.77 \\
2 & 0.075 & - & 5 & 2.40 \\
3 & 0.015 & - & 1 & 0.48 \\
4 & - & 0.150 & 10 & 4.77 \\
5 & - & - & - & 0
\end{tabular}

a Dry mass of the film corresponds to the mass measured after the film was dried to constant mass in a static oven at $37^{\circ} \mathrm{C}$

controls. The compositions of the films prepared are given in Table 1.

\subsection{Characterization of the zeolite/PVA film}

\subsubsection{Morphology}

The surface and cross sectional morphology of the films were investigated by scanning electron microscope (XL30S FEG SEM, Philips). The dried circular film specimens were deposited onto aluminium specimen stubs using carbon tape and coated with gold on an ion sputter (SC7610 Sputter Coater, Polaron) for $60 \mathrm{~s}$ at $20 \mathrm{~mA}$ under $8 \times 10^{-2}$ mbar.

\subsubsection{Elemental composition}

Surface elemental compositions of some films were analyzed via energy dispersive spectroscopy (EDX) coupled to the scanning electron microscope (XL-30S FEG SEM, Philips). The average surface elemental compositions were determined based on the data collected from six different regions on the film surfaces. The PVA powder used in the preparation of the films was also analysed by EDX.

\subsubsection{Crystallinity}

Crystallinity of the films was checked by X-ray diffractometer (X'Pert Pro, Philips) equipped with Ni-filtered $\mathrm{CuK} \alpha$ radiation source $(\lambda=0.1540560 \mathrm{~nm})$ over $2 \theta$ range of $5^{\circ}$ to $40^{\circ}$ at a $10.15 \mathrm{~s}$ measurement time per step, and a step size of $0.01671^{\circ}$. The X-ray source was operated at $40 \mathrm{~mA}$ and $45 \mathrm{kV}$.

Polymers may consist of both crystalline and amorphous phases. In the X-ray diffractogram of a polymer, a broad region under the sharp peaks is related to the amorphous phase. The percent crystallinity $\left(X_{c}\right)$ is defined as follows:

$X_{c}=I_{c} /\left(I_{a}+I_{c}\right)$ 
where $I_{c}$ is the sum of intensities of the crystalline reflections and $I_{a}$ is the intensity of the amorphous reflection.

\subsubsection{Thermal analysis}

Thermal gravimetric analyses (TGA) of the films and powder PVA were performed on a thermal gravimetric analyser (TGA-51, Shimadzu) up to $400{ }^{\circ} \mathrm{C}$ at a heating rate of $10{ }^{\circ} \mathrm{C} / \mathrm{min}$ under $40 \mathrm{~mL} / \mathrm{min}$ nitrogen flow. The melting and decomposition behaviour of the films were studied using a differential scanning calorimeter (DSC-50, Shimadzu). Approximately $3 \mathrm{mg}$ of the film was placed in an aluminium cell and heated from 30 to $400{ }^{\circ} \mathrm{C}$ at a heating rate of $10{ }^{\circ} \mathrm{C} / \mathrm{min}$ under $40 \mathrm{~mL} / \mathrm{min}$ nitrogen flow.

\subsubsection{Swelling behaviour}

Swelling tests were carried out in $50 \mathrm{~mL}$ deionized water at $37{ }^{\circ} \mathrm{C}$ in a thermo shaker (Max-Q 4000, Barnstead). The discs of diameter $20 \mathrm{~mm}$ were first dried at $37{ }^{\circ} \mathrm{C}$ until constant mass and then immersed in deionized water for 1 , 2, 4, 24, and $48 \mathrm{~h}$. At the end of the each immersion period, the discs were carefully removed from the water, excess water on the surface was wiped off with a filter paper, and then the discs were weighted. Percent equilibrium degree of swelling (EDS) and equilibrium water content (EWC) of the films were calculated as,

$$
\begin{aligned}
& \operatorname{EDS}(\%)=\left(m_{f}-m_{i}\right) \times 100 / m_{i} \\
& \operatorname{EWC}(\%)=\left(m_{f}-m_{i}\right) \times 100 / m_{f}
\end{aligned}
$$

where $m_{i}$ and $m_{f}$ are the initial (dry) and final masses of the films, respectively. The swelling tests were performed on three specimens for each film and the average EDS and EWC values were reported.

\subsubsection{Colour analysis}

Colour of the films were examined quantitatively using a handheld reflection spectrophotometer, AvaMouse, which is connected to AvaLight-DHS (Deuterium-Halogen Light Source) (Avantes Inc.) in the wavelength range of $380-780 \mathrm{~nm}$ at room temperature. The equipment was calibrated with the measurement of a pure white standard (100\% reflection) and a black box (zero reflection) before the colour analysis of the films. The measurements were calculated based on the $2^{\circ}$ standard observer and CIE (Commission Internationale d'Eclairage) standard illuminant D65.

\subsubsection{Dissolution tests}

Stability of the films upon swelling in water and fractional dissolution of the PVA were examined through dissolution tests. Following the swelling tests, the discs were dried at $37{ }^{\circ} \mathrm{C}$ in a static oven until constant mass. Percent gelation degree was calculated as:

Gelation degree $(\%)=m_{\mathrm{f}}^{\prime} \times 100 / m_{i}$

where $m_{\mathrm{f}}^{\prime}$ is the mass of the film after the soluble part was removed and $m_{i}$ is the initial (dry) mass the film.

\subsubsection{Mechanical properties}

Mechanical properties of the films were determined by a universal material testing instrument (AG-I $250 \mathrm{kN}$, Shimadzu) using the rectangular specimens $(8 \mathrm{~cm} \times 1 \mathrm{~cm})$. Prior to the mechanical tests, the specimens were dried in a static oven at $37{ }^{\circ} \mathrm{C}$ until constant mass and then conditioned in a climatic chamber (Angelantoni Industrie) at $23{ }^{\circ} \mathrm{C}$ and $55 \%$ relative humidity until constant mass (approximately for 1 week). The static tensile tests were conducted on the conditioned specimens at room temperature and humidity in accordance with ASTM D638. The maximum force applied was $500 \mathrm{~N}$ and the speed of the streching was kept at $5 \mathrm{~mm} / \mathrm{min}$. The ultimate tensile stress (UTS) and elongation at break values were then calculated from the stress versus strain graphs. At least four specimens were tested for each film.

\subsubsection{Cobalt release}

Amount of cobalt released from the Co-zeolite/PVA films upon immersion in $50 \mathrm{~mL}$ of deionized water was determined at $37{ }^{\circ} \mathrm{C}$. The release experiments were performed on three replicates for each film. At the end of the contact period of $24 \mathrm{~h}$, the discs were removed from the water, the solutions for the replicates were combined and analyzed by ICP-AES (Liberty Series II, Varian).

\subsubsection{Antibacterial activity}

Antibacterial activities of the films were tested against the reference strains of Escherichia coli (NRLLB 3008) and Staphylococcus aureus (ATCC 29213) by the disc-diffusion method. $19 \mathrm{~mL}$ of Mueller-Hinton agar was inoculated with $0.5 \mathrm{~mL}$ of the overnight-grown bacterial strains $\left(\sim 10^{8} \mathrm{cfu} / \mathrm{mL}\right)$. The dry circular film specimens were placed on the inoculated agar and incubated at $37{ }^{\circ} \mathrm{C}$ for $24 \mathrm{~h}$. At the end of the incubation period, no clear zones could be observed around none of the discs. This might be attributed to incomplete contact of the discs with the agar, thereby inhibition of the cobalt release from the dry films. Thus, the antibacterial activity tests were performed using the partially swollen discs, but again none of the discs exhibited a clear zone around. In the literature confinement of the bacterial growth inhibition zones around $\mathrm{Ag}^{+}$-zeolite 

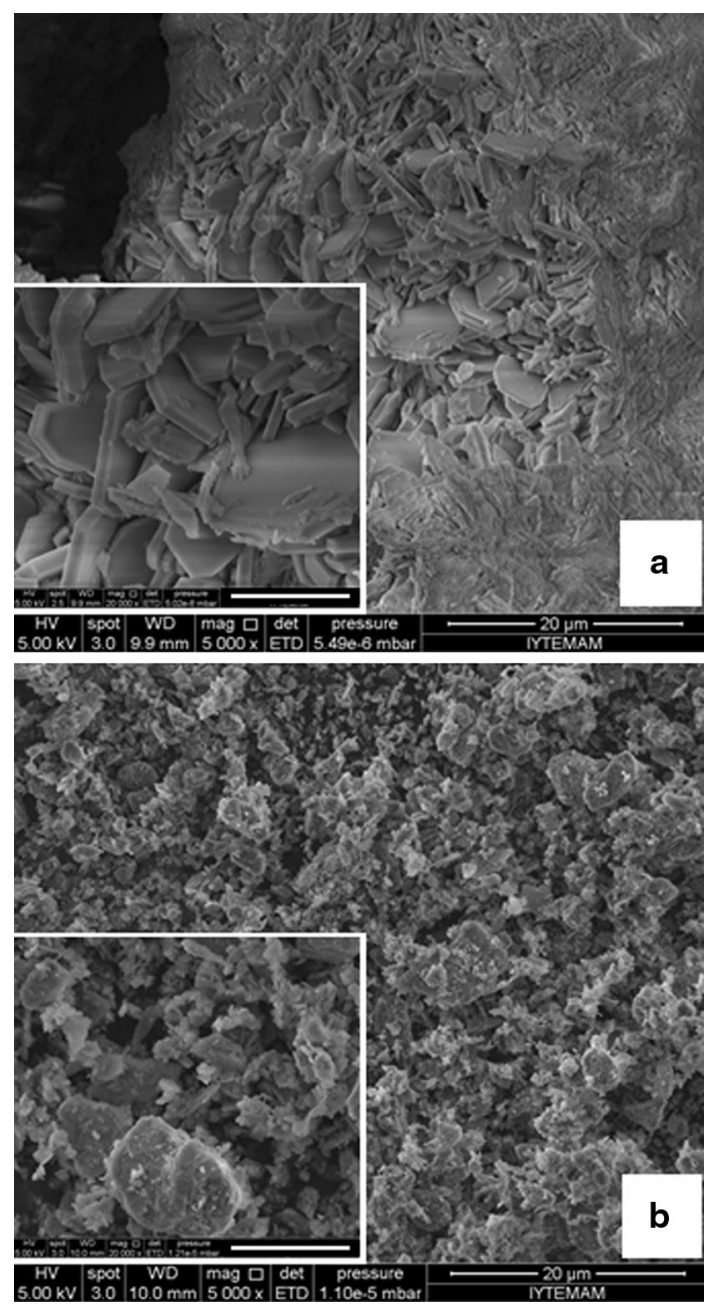

Fig. 1 Scanning electron micrographs of the zeolitic tuff as-supplied (a) and after the size reduction process (b) (scale is 5 micron for the inlet figures)

beta/polyurethane and zeolite A/polyurethane composite discs to a very limited environment $(\sim 1-2 \mathrm{~mm})$ was attributed to the slow diffusion rate of $\mathrm{Ag}^{+}$ion in the solidlike agar medium [13]. The mechanism of the antimicrobial effect of zeolite/polyurethane composites is based on the diffusion of the ions from the bulk to the surface where they interact with the microbial cells. Water uptake is a key factor since it can influence the diffusion of the zeolite and ions in a positive way [17]. Thus in the present study, it was decided to perform the antibacterial tests in suspension. Each disc was immersed in $1.5 \mathrm{~mL}$ of nutrient broth contained in a well of Corning 24 well plate. The nutrient broth was inoculated with $15 \mu \mathrm{L}$ of the overnight-grown E. coli cell culture $\left(\sim 10^{8} \mathrm{cfu} / \mathrm{mL}\right)$. The film was fixed in the well using a stainless steel coil in such a manner that the film does not interfere transmission of the ultraviolet light. The absorbance values at $620 \mathrm{~nm}$ were recorded continuously for the incubation period of $24 \mathrm{~h}$ at $37{ }^{\circ} \mathrm{C}$ in

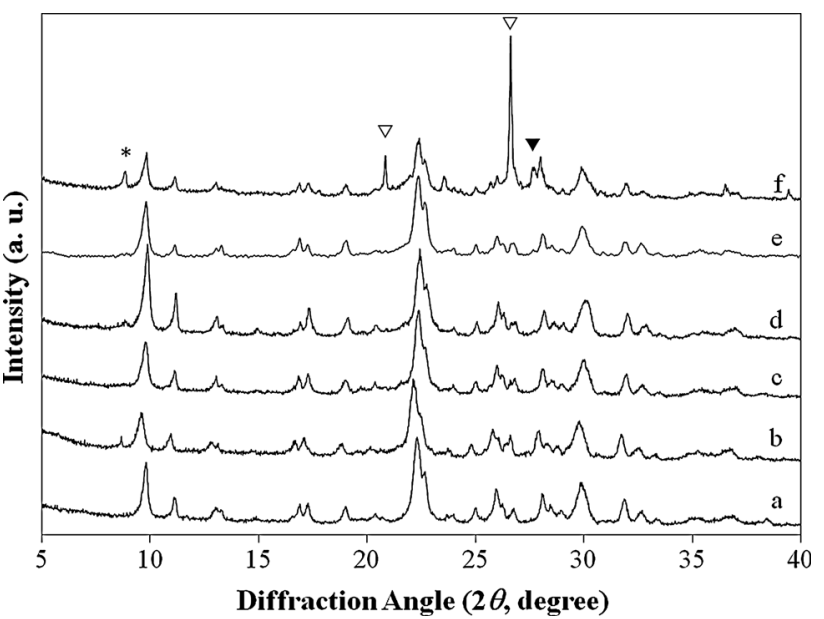

Fig. 2 X-Ray powder diffractograms of the clinoptilolite reference (a), zeolitic tuff (b), zeolite powder (c), Na-zeolite (d), Co-zeolite (e), and fraction discarded during the size reduction process (f) (asterisk biotite, inverted open triangle quartz, inverted filled triangle feldspars, other reflections are for clinoptilolite)

an UV-VIS spectrophotometer (Varioskan Flash, Thermo). The absorbance values were also recorded at the end of the incubation period after the films were removed from the wells. Absorbance values for the nutrient broth in which only the stainless steel string was immersed were recorded as control. Growth of the $E$. coli cells during the incubation was also followed. All the samples, including the controls, were tested in two replicates.

\section{Results and discussion}

\subsection{Characterization of the zeolite powders}

Clinoptilolite crystals with typical coffin-like morphology together with the other phases were observed in the scanning electron micrographs of the tuff as shown in Fig. 1a. The zeolite fine powder had a uniform particle size distribution (Fig. 1b). It was not possible to see the complete clinoptilolite crystals in the micrograph of the fine powder since the particle size was below the crystal size of the clinoptilolite. Particle size distribution analysis of the fine zeolite powder confirmed that $95 \mathrm{wt} \%$ of the particles had below $5 \mu \mathrm{m}$ diameter.

X-Ray powder diffractograms of the zeolitic tuff, powders, and the clinoptilolite reference mineral are shown in Fig. 2. The qualitative mineralogical analysis revealed that the tuff contains predominantly clinoptilolite (JCPDS 25-1349) as well as quartz, feldspars, and biotite as mineral impurities. The size reduction-separation process caused the intensities of clinoptilolite reflections to increase and the reflections belonging to the mineral impurities to disappear. The clinoptilolite contents of the zeolitic tuff and 
Table 2 Elemental compositions of the zeolite powders

\begin{tabular}{llll}
\hline Element & \multicolumn{3}{l}{ Elemental composition (wt\%) } \\
\cline { 2 - 4 } & Zeolite & Na-zeolite & Co-zeolite \\
\hline $\mathrm{Si}$ & 68.56 & 66.03 & 65.38 \\
$\mathrm{Al}$ & 24.05 & 14.60 & 14.22 \\
$\mathrm{~K}$ & 7.28 & 5.84 & 5.46 \\
$\mathrm{Na}$ & 1.23 & 10.18 & 5.50 \\
$\mathrm{Ca}$ & 4.69 & 0.52 & 0.52 \\
$\mathrm{Mg}$ & 1.72 & 0.67 & 0.66 \\
$\mathrm{Fe}$ & 2.47 & 2.16 & 2.23 \\
$\mathrm{Co}$ & 0 & 0 & 6.02 \\
\hline
\end{tabular}

zeolite powder were determined as 75 and $83 \mathrm{wt} \%$, respectively, designating concentration of the clinoptilolite phase in the zeolite powder by the size reduction-separation process employed. The reflections in the X-ray diffractogram of the fraction discarded during the size reduction-separation process were associated with the mineral impurities. The $\mathrm{NaCl}$ treatment and cobalt loading processes did not led to any significant change in the crystal structure of the zeolite.

From chemical compositions of the zeolite powders given in Table $2, \mathrm{SiO}_{2} / \mathrm{Al}_{2} \mathrm{O}_{3}$ of the zeolite powder was determined as 5.21. The theoretical cation exchange capacity (TCEC) of the powder was calculated as $1.07 \mathrm{meq} / \mathrm{g}$. After the $\mathrm{NaCl}$ treatment, the TCEC increased to $1.18 \mathrm{meq} / \mathrm{g}$. During the cobalt loading, the cobalt ions in the solution were mainly exchanged with the sodium ions in the zeolite.

From the results of antibacterial tests of the powders (not shown), the zeolite and Na-zeolite powders did not exhibited antibacterial activity against either E. coli or S. aureus. After the cobalt loading, the zeolite gained antibacterial activity. The diameter of the growth inhibition zone around the $8 \mathrm{~mm}$ diameter Co-zeolite disc was $21.48 \pm 0.16 \mathrm{~mm}$ for $E$. coli and $16.70 \pm 1.26 \mathrm{~mm}$ for $S$. aureus.

\subsection{Characterization of the films}

\subsubsection{Morphology}

Figure 3 shows the representative SEM images from the surfaces of the films. All the films presented very similar morphological aspects on the surface showing uniform and continuous films. At some regions on the surface, defects and particles with voids around them were observed. The EDX analyses on these defects revealed that they were not zeolite.

In the SEM images from the cross sections of the films shown in Fig. 4, it was observed that the zeolite particles were distributed throughout the polymer matrix. Cross sectional porosity of the film was found to be dependent on its zeolite content. The thicknesses of the films were uniform. The films have a symmetric structure.

\subsubsection{Elemental composition}

Representative EDX spectra from the surfaces of the films 1 and 5 are shown in Fig. $5 a$ and b, respectively. These films have identical surface chemical composition with $69 \mathrm{wt} \%$ carbon and $31 \mathrm{wt} \%$ oxygen. The films were found to have higher carbon and lower oxygen contents than the powder PVA used in preparation of the films (the PVA powder has $57 \mathrm{wt} \%$ of carbon and $43 \mathrm{wt} \%$ of oxygen according to the EDX analysis). This could be explained by removal of some $\mathrm{O}-\mathrm{H}$ groups of the PVA as water molecules during the freezing-thawing process according to the following reaction [47]:

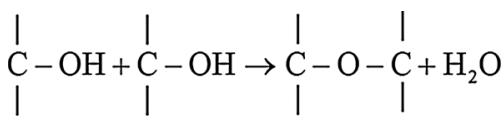

\subsubsection{Crystallinity}

XRD diffraction patterns of the films, shown in Fig. 6, presented a strong peak at $19.7^{\circ} 2 \theta$ corresponding to (101) reflection of the monoclinic PVA crystal, and at $23.1^{\circ} 2 \theta$ corresponding to the PVA crystalline phase [48, 49]. The other peaks at $9.8^{\circ}, 22.3^{\circ}$, and $29.8^{\circ} 2 \theta$ were contributed from the clinoptilolite crystals in the film.

The intensity of $19.7^{\circ} 2 \theta$ reflection was influenced by the zeolite content of the films. PVA is usually crystalline due to the strong intermolecular interaction between PVA chains through intermolecular hydrogen bonding. The intensity of reflection and size of the PVA crystals are determined by the number of PVA chains packing together. The interaction of PVA chains with the zeolite particles might lead to a decrease in the intermolecular interaction between the PVA chains and thus in the intensity of the $19.7^{\circ} 2 \theta$ reflection [50]. Many studies reported that incorporation of inorganic particles into PVA resulted in a lower X-ray crystal diffraction intensity than the pure PVA film [51-53]. Furthermore, the decrease in the intensities of the crystalline PVA reflections in the presence of the zeolite particles might be due to the larger mass absorption coefficients of $\mathrm{Si}, \mathrm{Al}$, and Co atoms as compared to those of $\mathrm{C}$ and $\mathrm{H}$ atoms in the pure PVA film. The fractional decrease in the intensity of an $\mathrm{X}$-ray beam as it passes through any homogeneous substance depends on the intensity of incident X-ray beam, sample thickness, and the X-ray mass absorption coefficient of the sample $[54,55]$. Presence of the elements with high mass absorption coefficient in the film limits the effective X-ray 

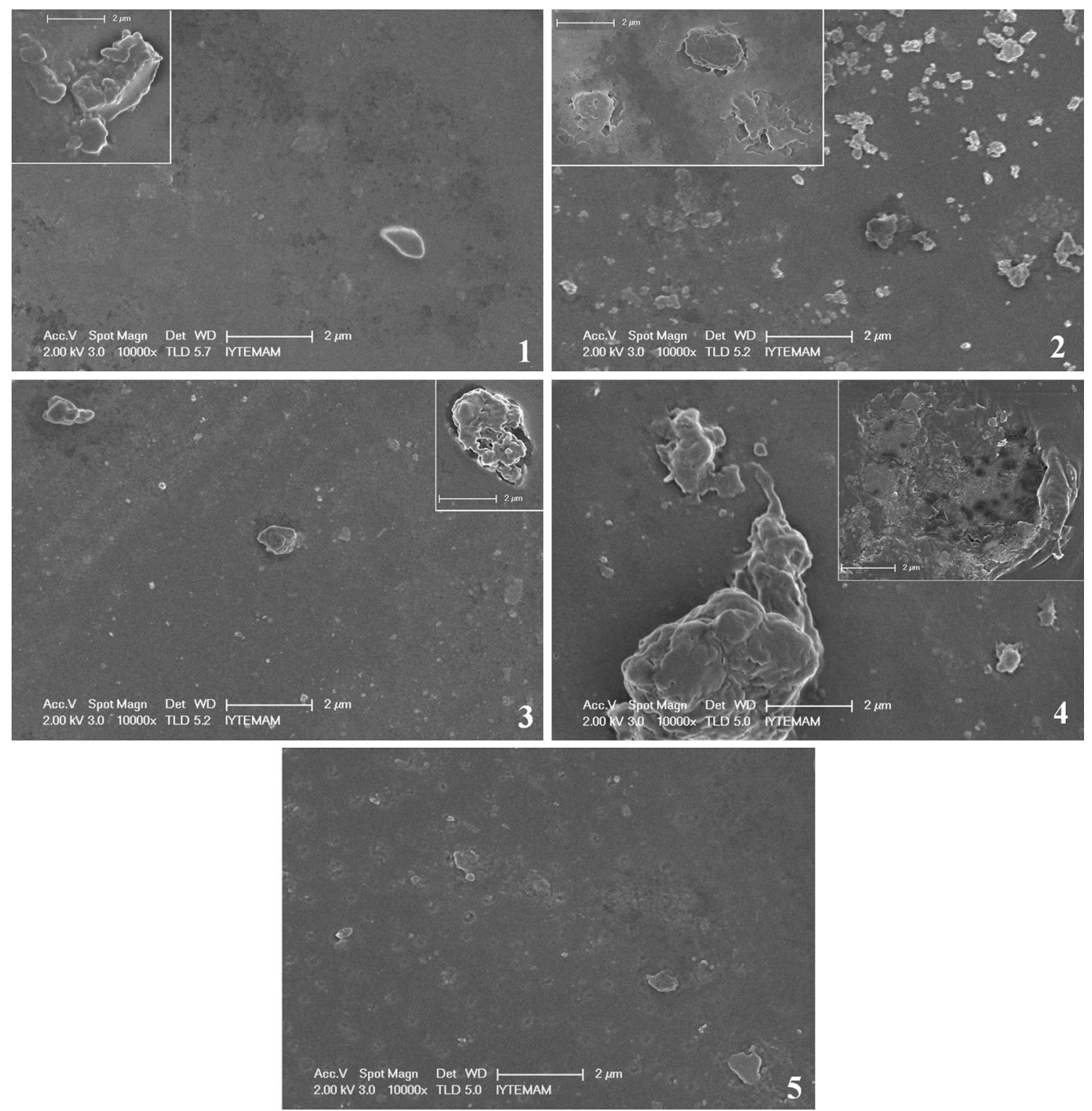

Fig. 3 Scanning electron micrographs of the surface of the films: film 1 (1), film 2 (2), film 3 (3), film 4 (4), film 5 (5) (scale bars are $2 \mu$ m)

penetration depth, so that the X-ray beam may not sample all depths of the film equally [56].

\subsubsection{Thermal analysis (TGA, DSC)}

The thermogravimetric (TG) curves of the films are presented in Fig. 7. The mass loss in the region of $80-200{ }^{\circ} \mathrm{C}$, about $6 \mathrm{wt} \%$, was due to loss of water, and that in the region of $250-400{ }^{\circ} \mathrm{C}$, approximately $60 \mathrm{wt} \%$, was due to decomposition of PVA. From the derivative TG (d-TG) curves (not shown), the maximum mass losses were noted around 150 and $305{ }^{\circ} \mathrm{C}$. Considering the second peak, there was no change in thermal stability of the pure PVA film compared to the powder PVA. Due to the presence of the Na-zeolite particles, the second peak shifted to higher temperatures indicating higher thermal stability of this film than the pure PVA film. This peak occurred at lower temperatures in the d-TG curves of the Co-zeolite/PVA films compared to that of the pure PVA film.

In the differential scanning calorimetry (DSC) curves of the films, presented in Fig. 8, the broad peak at approximately $150{ }^{\circ} \mathrm{C}$ represents loss of the residual water present in the films, as confirmed by the TG analysis. There were two other well-defined endothermic transitions, one located at $225{ }^{\circ} \mathrm{C}$ and the other in the range of $285-310^{\circ} \mathrm{C}$ depending on the zeolite content of the film. The transition at $225^{\circ} \mathrm{C}$ corresponds to the melting of the PVA [40]. Presence of the zeolite did not cause a shift of the melting temperature. The transition reaction in the range of 285-310 ${ }^{\circ} \mathrm{C}$ corresponds to decomposition of the PVA. 

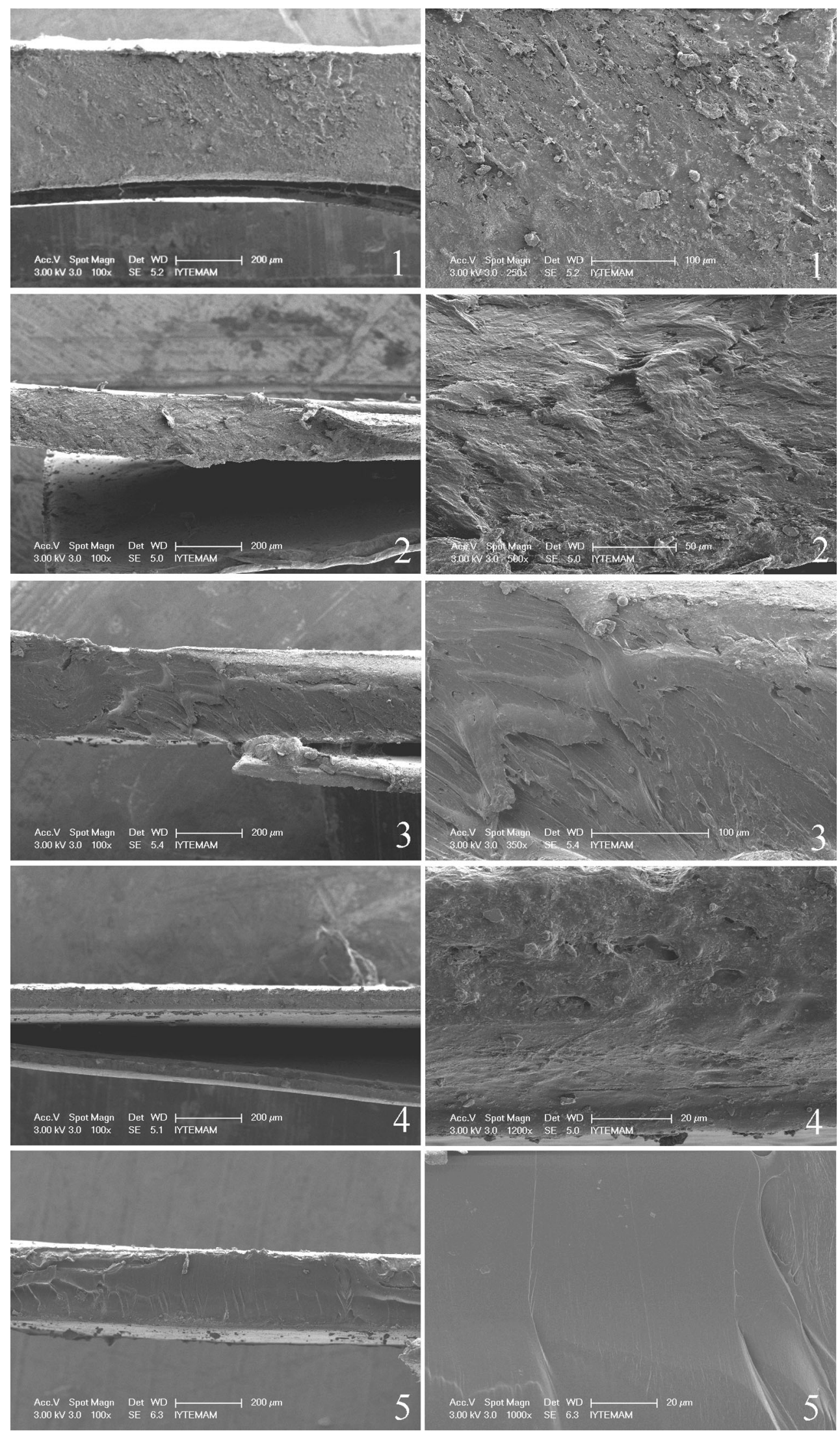

Fig. 4 Scanning electron micrographs from cross sections of the films: film 1 (1), film 2 (2), film 3 (3), film 4 (4), film 5 (5) 


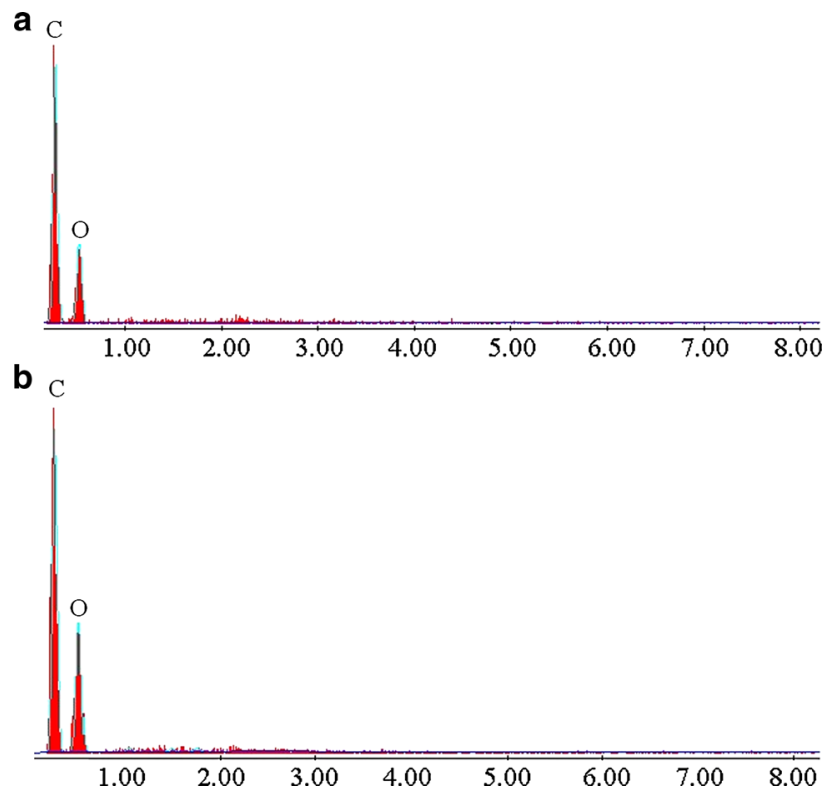

Fig. 5 Representative EDX spectra from surfaces of films 1 (a) and 5 (b)

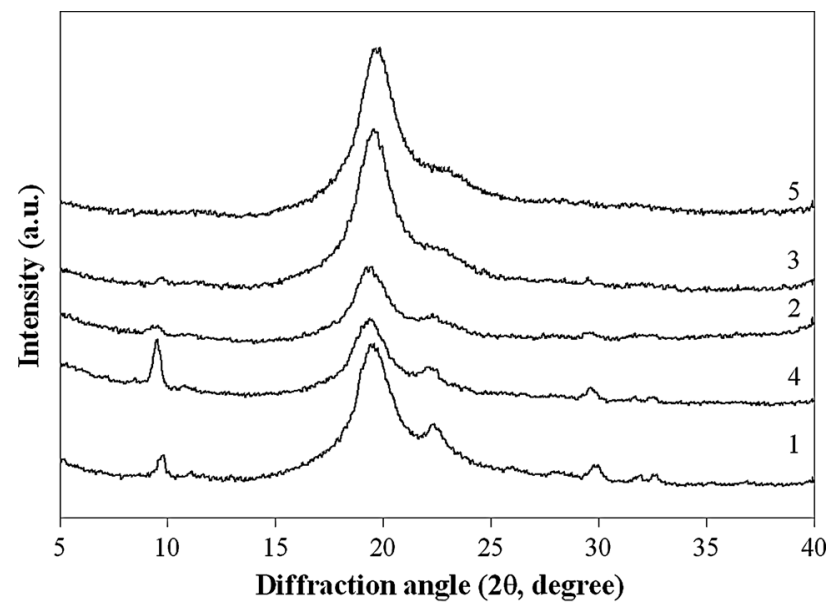

Fig. 6 X-ray diffractograms of the films: film 1 (1), film 2 (2), film 3 (3), film 4 (4), film 5 (5)

The decomposition temperature decreased, while the associated heat increased, as the Co-zeolite content of the film increased. The film with Na-zeolite decomposed at higher temperature than that containing the same amount of Co-zeolite. It is known that cobalt is one of the transition metals included in additives which act as catalyst to speed up the normal oxidative degradation of polymers.

Degrees of crystallinity of the films were calculated by analysing the melting peak at $225{ }^{\circ} \mathrm{C}$. Heat required for melting of the film $(\Delta H)$ was determined by integrating the area under this peak over the temperature range of 190$240{ }^{\circ} \mathrm{C}$ and found to be increased with the increasing Cozeolite content of the film. Degrees of crystallinity of the films were calculated by using Eq. 5 [57]:

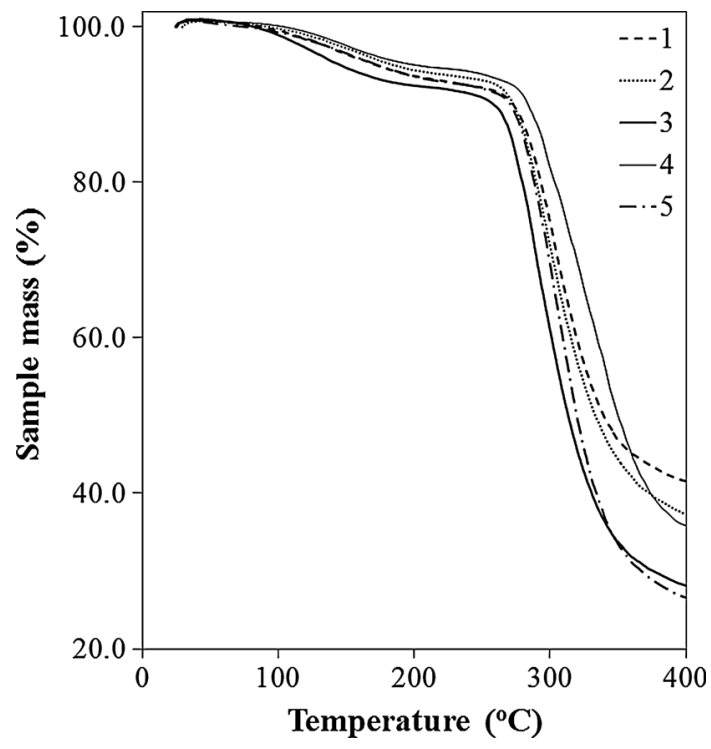

Fig. 7 TGA curves for the films: film 1 (1), film 2 (2), film 3 (3), film 4 (4), film 5 (5)

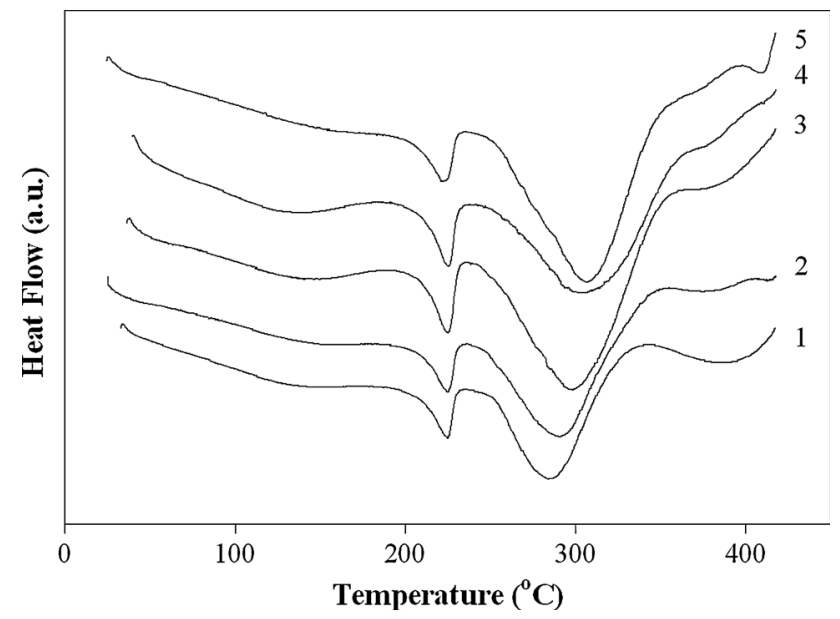

Fig. 8 DSC curves for the films: film 1 (1), film 2 (2), film 3 (3), film 4 (4), film 5 (5)

$X=\left(\Delta H / \Delta H^{*}\right) / W_{\mathrm{PVA}}$

where $X$ is the degree of crystallinity of the film, $\Delta H$ is the heat required for melting of the film, $\Delta H^{*}$ is the heat of fusion of the hypothetically $100 \%$ crystalline PVA sample, and $W_{\mathrm{PVA}}$ is the weight fraction of PVA in the film. The $\Delta H^{*}$ value is reported in the literature as $138.6 \mathrm{~J} / \mathrm{g}$ [35].

The crystalline state is defined as one that diffracts $\mathrm{X}$-rays and exhibits the first-order transition (melting) [53]. The crystallinity degrees of the films determined from the $\mathrm{X}$-ray diffraction (Eq. 1) and DSC analyses are given in Table 3. The crystallinity of PVA in the films determined by the two different methods were close to each other and they were in the range of 75-85\%. 
Table 3 Comparison of degrees of crystallinity of the films by X-ray diffraction and DSC analyses

\begin{tabular}{llllll}
\hline Film & $\begin{array}{l}\text { Zeolite content of } \\
\text { dry film (wt\%) }\end{array}$ & $\begin{array}{l}\text { Melting } \\
\text { temperature } \\
\left({ }^{\circ} \mathrm{C}\right)\end{array}$ & $\begin{array}{l}\text { Heat of } \\
\text { fusion }(\mathrm{J} / \\
\mathrm{g})\end{array}$ & $\begin{array}{l}\text { Degree of } \\
\text { crystallinity } \\
(\%)\end{array}$ \\
\cline { 5 - 6 } & & 224.8 & -49.9 & 75 & 85 \\
\hline 1 & 4.77 & 224.8 & -51.0 & 77 & 75 \\
2 & 2.40 & 225.0 & -53.7 & 81 & 85 \\
3 & 0.48 & 225.3 & -56.2 & 85 & 79 \\
4 & 4.77 & 222.8 & -50.5 & 73 & 85 \\
5 & 0 & & & & \\
\hline
\end{tabular}

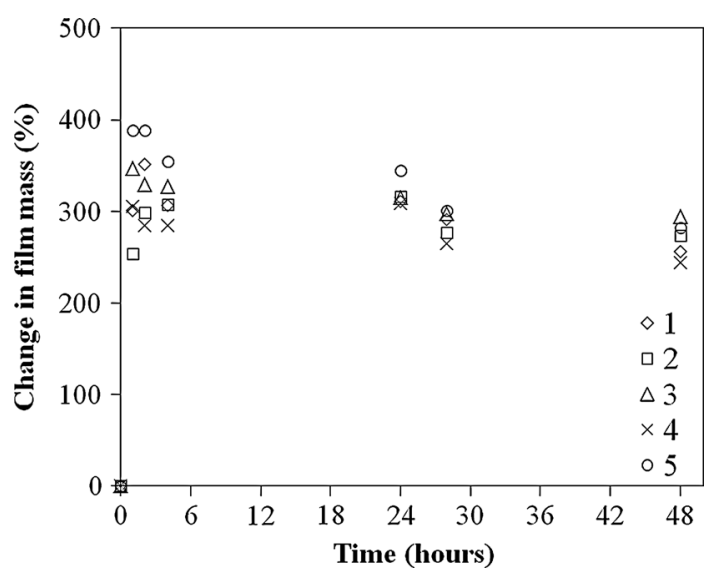

Fig. 9 Swelling kinetics: film 1 (1), film 2 (2), film 3 (3), film 4 (4), film $5(\mathbf{5})$

\subsubsection{Swelling behaviour}

Figure 9 shows the swelling kinetics of the films. The mass of all films increased rapidly within the first $2 \mathrm{~h}$, then stabilized over the next $22 \mathrm{~h}$ period, and declined slightly within the next $24 \mathrm{~h}$ of immersion. This behaviour might be explained by the swelling of the films within the first $2 \mathrm{~h}$ of immersion, then diffusion of the hydrated uncrosslinked PVA from the swollen films.

Loss of water from hydrogels when exposed to different environments is called syneresis [58]. Syneresis can be observed when the amount of diluent in a swollen polymer exceeds the solubility limit and the water molecules start to leave the structure [59]. However in the present case, uncrosslinked PVA molecules which are hydrated with water were thought to diffuse from the swollen film phase to the water phase.

It was not possible to analyse the swelling mechanism since there was not enough data within the first $2 \mathrm{~h}$ of the immersion. During immersion of the films in the deinozied water for longer than $2 \mathrm{~h}$, the uncrosslinked PVA which were hydrated with water molecules start to diffuse from



Fig. 10 Diffusion kinetics of the hydrated uncrosslinked PVA from swollen films: film 1 (1), film 2 (2), film 3 (3), film 4 (4), film 5 (5)

Table 4 Kinetic parameters for diffusion of the hydrated uncrosslinked PVA in the swollen films

\begin{tabular}{llll}
\hline Film & $r^{2}$ & $k$ & $n$ \\
\hline 1 & 0.799 & 0.071 & 0.207 \\
2 & 0.999 & 0.003 & 0.482 \\
3 & 0.974 & 0.024 & 0.314 \\
4 & 0.919 & 0.041 & 0.252 \\
5 & 0.999 & 0.012 & 0.366 \\
\hline
\end{tabular}

the film into the water and caused the film mass to decrease. Kinetics of the mass loss can be expressed as:

$M_{t} / M_{\infty}=k t^{n}$

where $M_{t}$ and $M_{\infty}$ represent the decrease in the film mass at time $t$ and at equilibrium, respectively, $k$ is a constant characteristic of the system, and $n$ is an exponent which represents transport modes inside the film and provides information about the transport mechanism. A value of $n \leq 0.5$ indicates a Fickian diffusion mechanism (the rate of diffusion is much lower than the rate of relaxation), a value of $0.5 \leq n \leq 1$ indicates that diffusion is anomalous or Fickian and $n=1$ implies case II (relaxation-controlled transport, diffusion is very fast contrary to the rate of relaxation). The constants $n$ and $k$ were calculated from the slope and intercept of the $\ln \left(M_{t} / M_{\infty}\right)$ versus $\ln t$ curves (Fig. 10) and given in Table 4.

The calculated $n$ values which were smaller than 0.5 indicated that the diffusion of the hydrated uncrosslinked PVA in the swollen films was governed by a Fickian diffusion mechanism. The diffusion coefficient for the hydrated uncrosslinked PVA in the swollen film was calculated by the following equation [60]:

$M_{t} / M_{\infty}=4\left(D t / \pi l^{2}\right)^{1 / 2}$ 


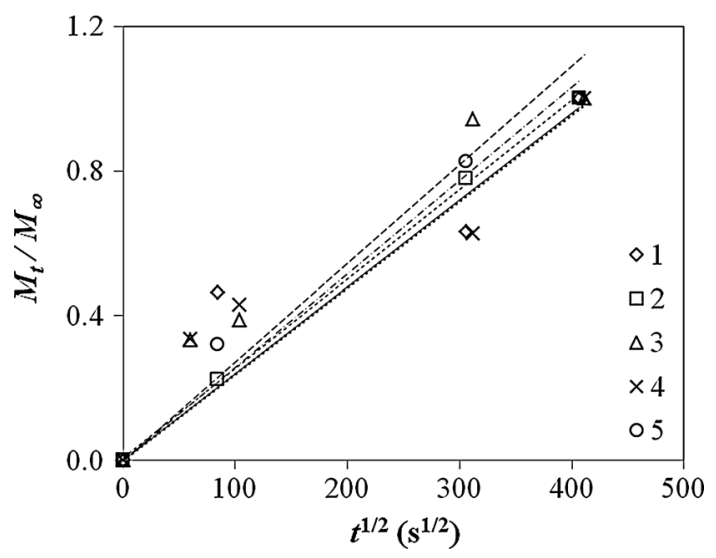

Fig. 11 The $M_{t} / M_{\infty}$ versus $t^{1 / 2}$ for diffusion of hydrated uncrosslinked PVA: film 1 (1), film 2 (2), film 3 (3), film 4 (4), film 5 (5)

Table 5 Diffusion coefficients for the hydrated uncrosslinked PVA in the swollen films

\begin{tabular}{lll}
\hline Film & $r^{2}$ & $D\left(\mathrm{~cm}^{2} / \mathrm{s}\right)$ \\
\hline 1 & 0.847 & $5.42 \times 10^{-10}$ \\
2 & 0.999 & $1.71 \times 10^{-10}$ \\
3 & 0.914 & $3.89 \times 10^{-10}$ \\
4 & 0.847 & $2.29 \times 10^{-11}$ \\
5 & 0.978 & $2.28 \times 10^{-10}$ \\
\hline
\end{tabular}

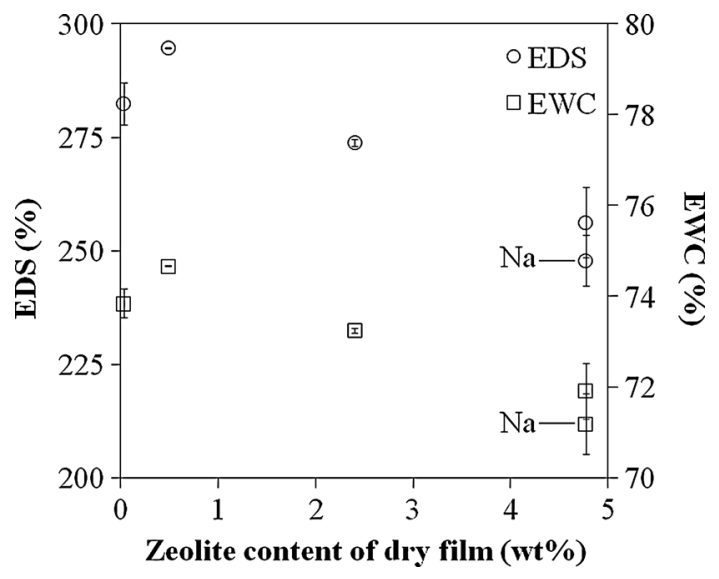

Fig. 12 Effect of zeolite content of the film on $E D S$ and $E W C$ of the film

where $l$ is the thickness of the film measured from the SEM micrographs (Fig. 4), and $D$ is the diffusion coefficient of the molecules from the film. From the $M_{t} / M_{\infty}$ versus $t^{1 / 2}$ plots shown in Fig. 11, the calculated diffusion coefficients and the regression coefficients $\left(r^{2}\right)$ are given in Table 5 . The diffusivity of hydrated uncrosslinked PVA in the films were in the range of $2.29 \times 10^{-11}-5.42 \times 10^{-10} \mathrm{~cm}^{2} / \mathrm{s}$.
Figure 12 shows dependence of the EDS and EWC of the film on its zeolite content. The EDS values were in the range of 248-295\% of the dry mass, so the films can be categorized as superabsorbent [61]. It can be seen that the EDS and EWC of the films increased with the increasing zeolite content up to a certain limit $(0.48 \mathrm{wt} \%)$, then decreased. The films have swelling capacity high enough to be used as a suitable wound dressing even for exudative wounds.

The volume of the films increased appreciably during the swelling test without disintegration as shown in Fig. 13. The pure PVA film has excellent transparency, while the films have become more and more opaque by the addition of zeolite in increasing amounts. The transparent nature of the pure PVA film indicates the homogeneous network structure. The opacity of the blend films might be attributed to the increased crystallinity and microphase separation which occurs in the early stage of the gelation process [62].

\subsubsection{Colour analysis}

The $\mathrm{L}^{*} \mathrm{a} * \mathrm{~b} *$ colour system was used in colour analysis of the films. This system can be visualized as a cylindrical coordinate system in which the axis of the cylinder is the lightness variable $L^{*}$, ranging from 0 to $100 \%$, and the radii are the chromaticity variables $a^{*}$ and $b^{*}$. Variable $a^{*}$ is the green (negative) to red (positive) axis, and variable $b^{*}$ is the blue (negative) to yellow (positive) axis [63]. Change in the colour parameters of the films as a function of their zeolite content are shown in Fig. 14. Generally as the Co-zeolite content of the film increased the parameter $a^{*}$ decreased, and the parameter $b^{*}$ increased indicating the colour became less red and more yellow. The lightness parameter $L^{*}$ decreased slightly for the films with higher zeolite content.

The colour analysis of the dry films indicated that the colour of the films was due to the coloured zeolite particles distributed in the hydrogel matrix. The $\mathrm{Fe}^{2+}$ ions in the zeolite oxidized to $\mathrm{Fe}^{3+}$ resulting in the colouring of the zeolite particles and thereby the films.

The colour difference between the zeolite-containing films and pure PVA film $\left(\Delta E_{a b}{ }^{*}\right)$ can be determined as:

$\Delta E_{a b} *=\left[(\Delta L *)^{2}+(\Delta a *)^{2}+(\Delta b *)^{2}\right]^{1 / 2}$

where $\Delta L^{*}, \Delta a^{*}$, and $\Delta b^{*}$ are differences between the corresponding colour parameters for the pure PVA film and zeolite-containing films. The colour difference calculated in this manner for each film is illustrated in Fig. 14d as a function of the film zeolite content. The higher zeolite content resulted in larger colour deviation from the colour of the pure PVA film. 


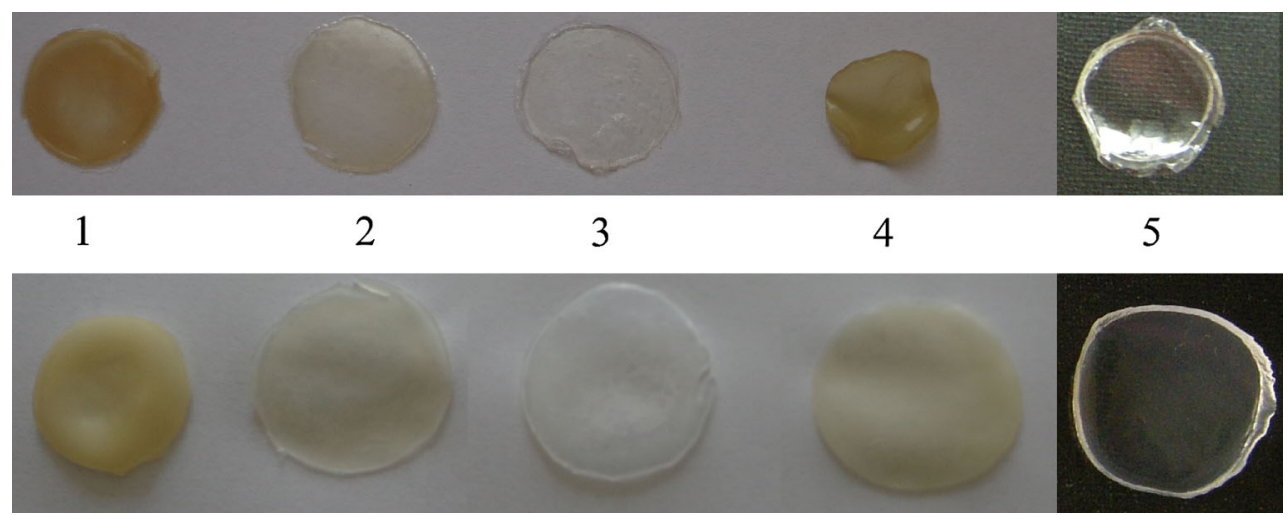

Fig. 13 Photographs of the films before (upper) and after (lower) the swelling test: film 1 (1), film 2 (2), film 3 (3), film 4 (4), film 5 (5)

Fig. 14 The colour parameters of the films: parameter $a^{*}(\mathbf{a})$, parameter $b^{*}(\mathbf{b})$, parameter $L^{*}$ (c), and colour difference between the zeolite-containing and pure PVA films (d) (solid symbols represent data for the Na-zeolite/PVA film)
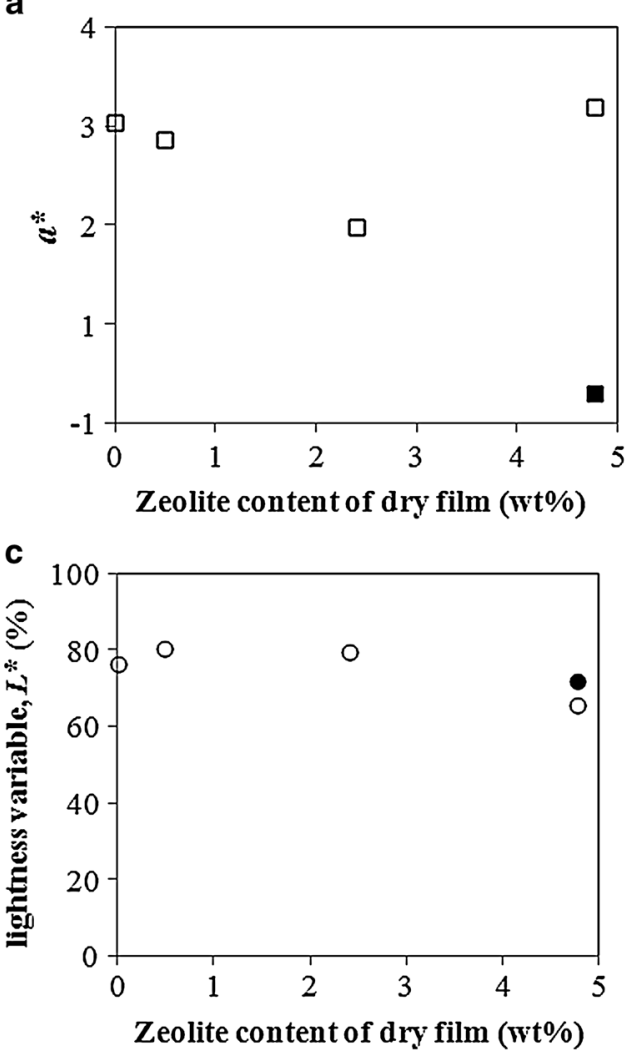

b

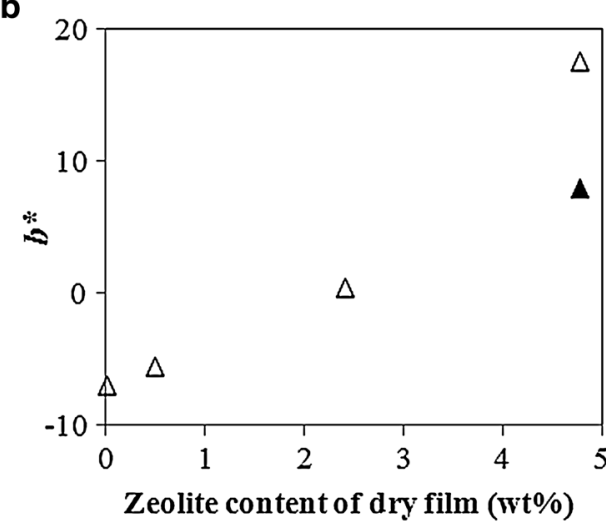

d

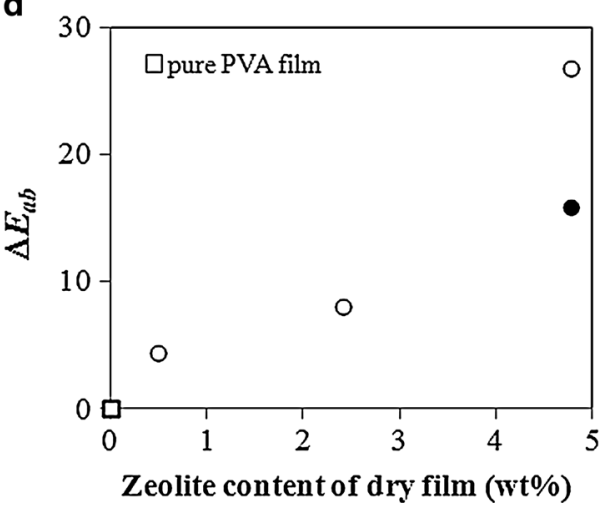

\subsubsection{Dissolution tests}

Figure 15 shows dependence of the gelation degree of the film on its zeolite content. The pure PVA film has gelation degree of around $70.5 \%$ indicating incomplete crosslinking of the PVA. The gelation degree decreased with the zeolite addition possibly due to interruption of the crosslinking and gelation processes in the presence of the zeolite particles [64].

The EDS and EWC of the film were related to its gelation degree as shown in Fig. 16, the higher the gelation degree, the lower the water uptake capacity. The crosslinking ratio is one of the most important factors that affect the swelling of hydrogels. Highly crosslinked hydrogels have a tighter structure, and swell less compared to the same hydrogels with lower crosslinking ratios. Crosslinking hinders the mobility of the polymer chain, hence lowers the swelling ratio [28, 65]. The equilibrium swelling degree decreases as the crosslinking degree increases. High crosslinking results in the number of the hydrophilic groups to decrease, i.e., the hydrogel to become more hydrophobic [31]. 


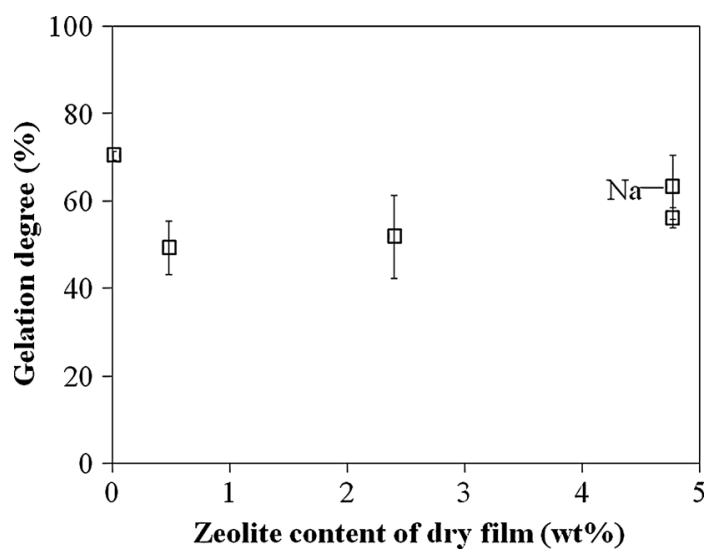

Fig. 15 Effect of zeolite content on the gelation degree of the films

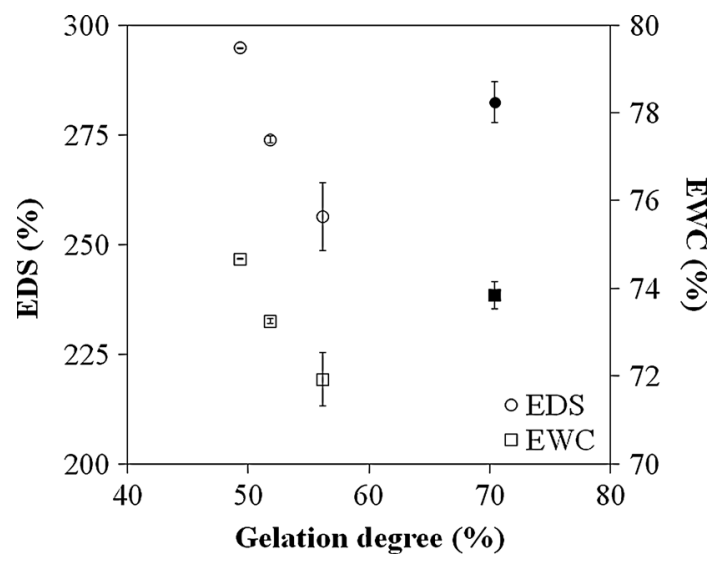

Fig. 16 Dependence of EDS and EWC on the gelation degree of the film (Solid symbols are for the pure PVA film)

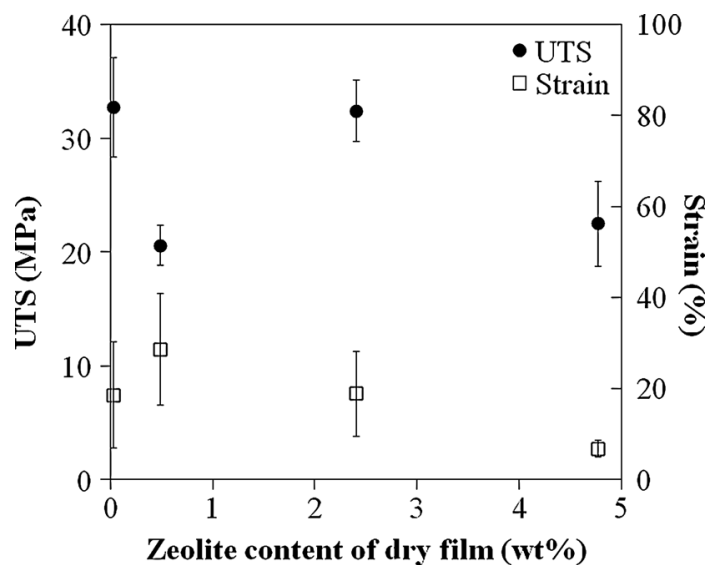

Fig. 17 Mechanical properties of the films

\subsubsection{Mechanical properties}

The average UTS of the films were found to be independent of their zeolite contents as shown in Fig. 17. Addition of the zeolite at the lowest amount caused the elongation at break (strain) to increase as compared to that for the pure

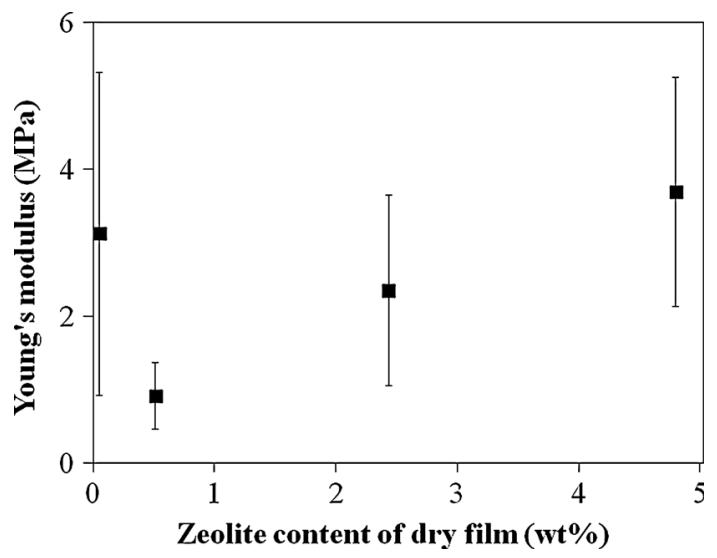

Fig. 18 Young's modulus of the films

PVA film, but at the higher zeolite contents the elongation values declined. It was reported that a polymer deformation mechanism usually involves amorphous polymer chain slippage, lamellae tilting and crystalline chain realignment, the separation of crystalline block segments, and the stretching, reorientation, and detachment of crystalline blocks and tie chains [66]. The lower elongation at break values for the films with the high zeolite contents might be explained by the prohibition of the PVA chain mobility as reported in the literature for the membranes with high fume silica content [52].

As illustrated in Fig. 18, the film with the highest zeolite content has almost the same Young's modulus of elasticity with the pure PVA film, while the films with lower zeolite contents have lower elasticity which might be related to the high degree of crystallinity of the films [67]. The changes in the mechanical properties might be due to decreased crosslinking of the polymer chains and polymer chain length in the presence of the zeolite particles [68].

The films had enough strength and flexibility to be used in wound dressing applications. They had tensile strength in the range of 20-30 MPa, elongation at break of 7-29\%, and modulus of elasticity of $1-4 \mathrm{MPa}$.

\subsubsection{Cobalt release}

The amount of cobalt released from the films upon immerion of the films in water increased with the Co-zeolite content of the film. No cobalt was detected in the water after $24 \mathrm{~h}$ immersion of the Na-zeolite/PVA and pure PVA films, since they did not have any cobalt initially. The amounts of cobalt remained in the films were calculated from the cobalt concentration in the water in which the films were immersed. Figure 19 shows the relationship between the cobalt concentration in the solution and that in the film at equilibrium. This figure can be interpreted as the adsorption isotherm data determined from the desorption 


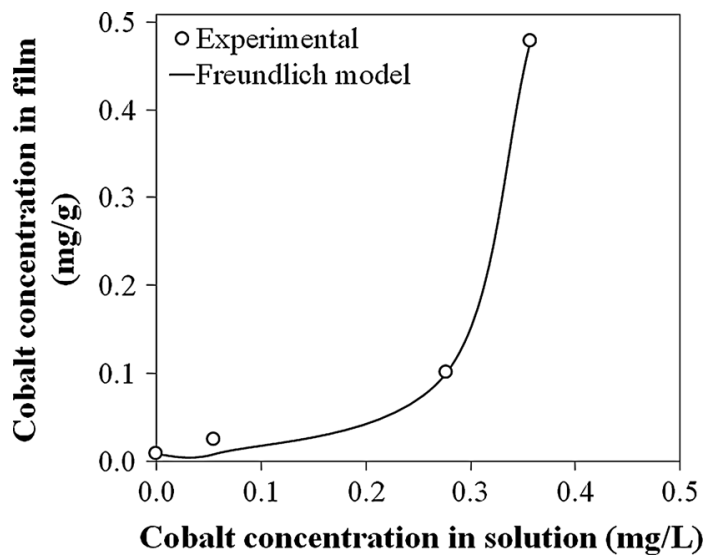

Fig. 19 Cobalt released from the film after immersion in water for $24 \mathrm{~h}$ at $37^{\circ} \mathrm{C}$

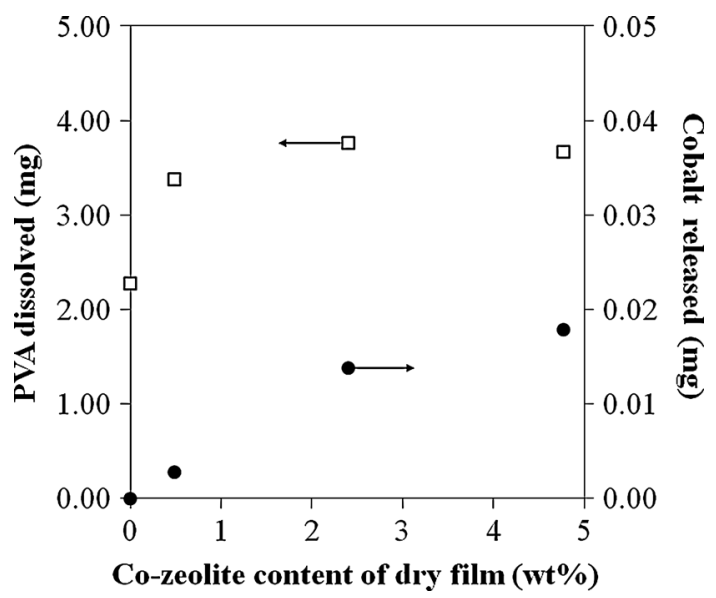

Fig. 20 Amount of PVA and cobalt released from the films after $24 \mathrm{~h}$ of immersion in water at $37^{\circ} \mathrm{C}$

data. This equilibrium data can be fitted to the Freundlich adsorption isotherm model;

$q_{e}=K_{F} C_{e}^{1 / n}$

where $q_{e}$ is the equilibrium cobalt concentration in the film $(\mathrm{mg} / \mathrm{g})$ and $C_{e}$ is the equilibrium cobalt concentration in the solution $(\mathrm{mg} / \mathrm{L})$. The Freundlich isotherm constants, $K_{F}$ and $n$, indicate sorption capacity of adsorbent (or the bonding energy) and intensity of adsorption, respectively. $K_{F}$ and $n$ were calculated as $340.546 \mathrm{~L} / \mathrm{g}$ and 0.156 , respectively. The Freundlich exponent $(n)$ value less than unity indicated the unfavorable isotherm.

Figure 20 shows the amount of PVA dissolved and cobalt released from the films during $24 \mathrm{~h}$ immersion in $50 \mathrm{~mL}$ water at $37{ }^{\circ} \mathrm{C}$ as a function of the Co-zeolite content of the film. The amount of PVA dissolved was almost independent of the film zeolite content. Not all the cobalt in the films was released.

For release of cobalt ions from the zeolite, the cobalt ions in the zeolite structure must be exchanged with other

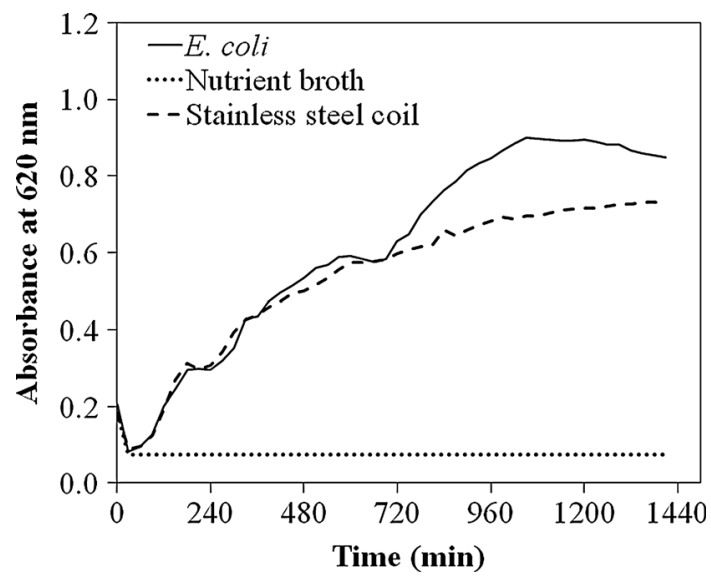

Fig. 21 Change in absorbance value at $620 \mathrm{~nm}$ during the antimicrobial tests in the nutrient media at $37{ }^{\circ} \mathrm{C}$ for the controls, i. e. the E. coli-inoculated nutrient broth (positive control 1), stainless steel coil in nutrient broth inoculated with E. coli (positive control 2), and the nutrient broth without any bacterial inoculation (negative control)

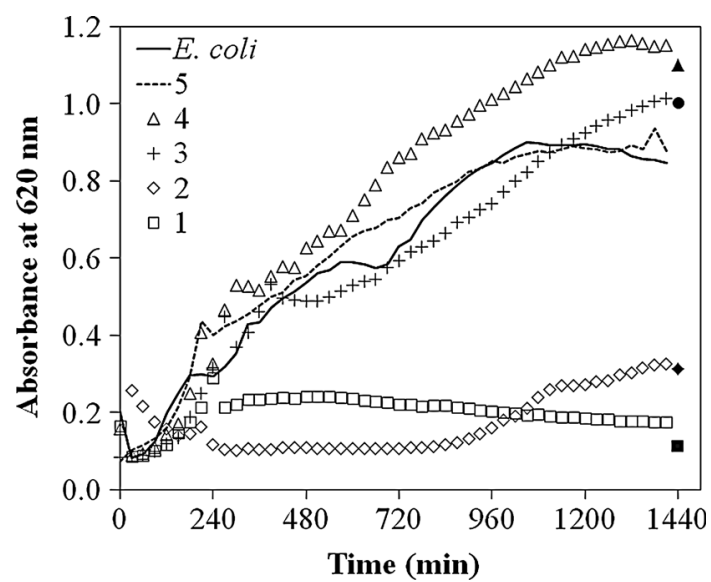

Fig. 22 Growth kinetics of the bacterial cells incubated with the films (solid symbols correspond to the absorbance values after the films were removed from the well): film 1 (1), film 2 (2), film 3 (3), film 4 (4), film 5 (5)

cations in the solution as reported in the literature $[1,4,7]$. On the other hand, under the conditions which the release experiments were performed in our study there was no such ions in the solution since the release experiments were performed in deionized water. The cobalt ions can be found in the zeolite in different states: as exchangeable cations or as bound physically. When the films are contacted with water, the physically bound cobalt is released from the zeolite particles to the water phase due to the concentration difference.

\subsubsection{Antibacterial activity}

Results of the antibacterial tests performed in the nutrient broth media are represented in Figs. 21 and 22. The growth of the bacterial cells was followed from the increasing 
absorbance values at $620 \mathrm{~nm}$. The stainless steel coil used to fix the film in the well did not affect the bacterial growth. The absorbance values recorded after the films were removed from the wells indicated that presence of the films in the well did not affect the transmission of the light. The absorbance values for the nutrient broth control were constant during the incubation period designating the lack of contamination of the broth. As seen in Fig. 22, the pure PVA film and Co-zeolite/PVA films with lower Co-zeolite content (films 3 and 4) did not inhibit the bacterial growth, while the films with higher Co-zeolite content exhibited significant inhibition effect. The bacterial growth inhibition of the films was found to be related with the amount of cobalt released from the films.

In the literature, increased antibacterial activity of the polymers containing silver-zeolite was observed with the higher amounts of silver ions released [4]. Matsumura et al. [1] proposed two possible successive processes may be involved in the antimicrobial action of silver-zeolite: First, the silver ion is taken in by the bacterial cells in contact with silver-zeolite, thereby inhibits several functions in the cells and consequently damages them. The second is the generation of reactive oxygen species, which are produced, possibly through the inhibition of respiratory enzymes by silver ion and attack the cell itself.

\section{Conclusion}

In this work, the natural zeolite powder loaded with cobalt(II) ions was used in the preparation of the zeolite/ PVA films in different amounts. The blend films were prepared by the freezing-thawing method and characterized for their physical, chemical, mechanical, and antibacterial properties. The films have equilibrium swelling degrees in the range of 248-295\% of the dry mass, while maintaining their integrity. The gelation degree was around $70 \%$ for the pure PVA film and decreased with the zeolite addition. The higher gelation degree gave rise to the lower water uptake capacity of the film. Ultimate tensile strengths and Young's modulus of the films were found to be in the 20-30 and 1-4 MPa range depending on the zeolite content of the film, respectively. Strength of the antibacterial activity of the films was dependent on the Co-zeolite content. The antibacterial tests performed in nutrient broth showed that the films with Co-zeolite content higher than $0.48 \mathrm{wt} \%$ has antibacterial activity against $E$. coli. The stronger antibacterial activity observed for the films with higher Co-zeolite content was attributed to the higher amounts of cobalt released when contacting the film with water. To evaluate the potential application of the films for medical purposes, such as wound dressing, optimization is necessary to produce zeolite/PVA hydrogel with required antibacterial and mechanical properties and minimal potential toxicity.

Acknowledgments This study was financially supported by Turkish Republic Prime Ministry State Planning Organization (DPT-2006 K120690, Determination of Effects of Zeolite on Health on Cellular and Molecular Level). The reference clinoptilolite mineral with $>95 \mathrm{wt} \%$ clinoptilolite content (27031, Castle Creek, Idaho) from Mineral Research, Clarkson, New York was kindly supplied by F. Mumpton. We would thank to Prof. Devrim Balköse for her valuable comments. We would also thank to Özen Özyurtsel and Selim Selimoğlu for their help in the experimental work.

\section{References}

1. Matsumura Y, Yoshikata K, Kunisaki S, Tsuchido T (2003) Mode of bactericidal action of silver zeolite and its comparison with that of silver nitrate. Appl Environ Microbiol 69:4278-4281

2. Matsuura T, Abe Y, Sato Y, Okamoto K, Ueshige M, Akagawa Y (1997) Prolonged antimicrobial effect of tissue conditioners containing silver-zeolite. J Dent 25(5):313-371

3. Hotta MNH, Yamamoto K, Aono M (1998) Antibacterial temporary filling materials: the effect of adding various ratios of AgZn-zeolite. J Oral Rehabil 25:485-565

4. Kawahara KTK, Morishita M, Uchida M (2000) Antibacterial effect of silver-zeolite on oral bacteria under anaerobic conditions. Dent Mater 16:452-455

5. Fumihiko A, Taro M, Yasushi Y, Masanori A, Yasutoshi C, Hiroki O, Toyokazu Y (2000) The evaluation of new wound dressing with antimicrobial delivery capability (non-woven sheet of $\mathrm{Ag}-\mathrm{Zn}$ zeolite impregnated Ca-alginate fiber). Jpn J Burn Inj 26:63-71

6. Rivera-Garza M, Olguín MT, García-Sosa I, Alcántara D, Rodríguez-Fuentes G (2000) Silver supported on natural Mexican zeolite as an antibacterial material. Microporous Mesoporous Mater 39:431-444

7. Inoue $Y$, Hoshino M, Takahashi H, Noguchi T, Murata T, Kanzaki Y, Hamashima H, Sasatsu M (2002) Bactericidal activity of $\mathrm{Ag}$-zeolite mediated by reactive oxygen species under aerated condition. J Inorg Biochem 92:37-42

8. Bruder MH, Ingram, AN (2013) Wound and therapy compress and dressing. US Patent 8420882 B2

9. Abe YUM, Takeuchi M, Ishii M, Akagawa Y (2003) Cytotoxicity of antimicrobial tissue conditioners containing silver-zeolite. Int J Prosthodont 16:141-144

10. Jensen JB, Torjalkar A (2003) Composition for wound dressings safely using metallic compounds to produce anti-microbial properties. US Patent 6592888

11. Castellano JJ, Shafii SM, Ko F, Donate G, Wright TE, Mannari RJ (2007) Comparative evaluation of silver-containing antimicrobial dressings and drugs. Int Wound J 4:114-122

12. Zhang Y, Zhong S, Zhang M, Lin Y (2009) Antibacterial activity of silver-loaded zeolite a prepared by a fast microwave-loading method. J Mater Sci 44:457-462

13. Ferreira L, Fonseca AM, Botelho G, Almeida- Aguia C, Neves IC (2012) Antimicrobial activity of faujasite zeolites doped with silver. Microporous Mesoporous Mater 160:126-132

14. Kamışoğlu K, Aksoy EA, Akata B, Hasırcı N, Baç N (2008) Preparation and characterization of antibacterial zeolite-polyurethane composites. J Appl Polym Sci 110:2854-2861

15. Boschetto DL, Lerin L, Cansian R, Pergher SBC, Di Luccio M (2012) Preparation and antimicrobial activity of polyethylene composite films with silver exchanged zeolite-Y. Chem Eng J 204-206:210-216 
16. Pehlivan H, Balköse D, Ülkü S, Tihmınlıoğlu F (2005) Characterization of pure and silver exchanged natural zeolite filled polypropylene composite films. Compos Sci Technol 65:2049-2058

17. Fernandez A, Soriano E, Hernandez-Munoz P, Gavara R (2010) Migration of antimicrobial silver from composites of polylactide with silver zeolites. J Food Sci 73:E186-E193

18. Kaali P, Pérez-Madrigal MM, Strömberg E, Aune RE, Czél Gy, Karlsson S (2011) The influence of $\mathrm{Ag}^{+}, \mathrm{Zn}^{2+}$ and $\mathrm{Cu}^{2+}$ exchanged zeolite on antimicrobial and long term in vitro stability of medical grade polyether polyurethane. eXPRESS Polym Lett 5:1028-1040

19. Fox S, Wilkinson TS, Wheatley PS, Xiao B, Morris RE, Sutherland A, John Simpson A, Barlow PG, Butler AR, Megson IL, Rossi AG (2010) NO-loaded $\mathrm{Zn}^{2+}$-exchanged zeolite materials: a potential bifunctional anti-bacterial strategy. Acta Biomater 6:1515-1521

20. Özmıç̧ı F, Balköse D, Ülkü S (2001) Natural zeolite polypropylene composite film preparation and characterization. J Appl Polym Sci 82:2913-2921

21. Aksoy EA, Akata B, Baç N, Hasurcu N (2007) Preparation and characterization of zeolite beta-polyurethane composite membranes. J Appl Polym Sci 104:3378-3387

22. Hasirci N (1991) Polyurethanes. In: Szycher M (ed) High performance biomaterials: comprehensive guide to medical and pharmaceutical application. Technomic Publishing Company, Lancaster, pp 71-90

23. Yasuyuki M, Kunihiro K, Kurissery S, Kanavillil N, Sato Y, Kikuchi Y (2010) Antibacterial properties of nine pure metals: a laboratory study using Staphylococcus aureus and Escherichia coli. Biofouling 26:851-858

24. Cerri G, de' Gennaro M, Bonferoni MC, Caramella C (2004) Zeolites in biomedical application: Zn-exchanged clinoptiloliterich rock as active carrier for antibiotics in anti-acne topical therapy. Appl Clay Sci 27:141-150

25. Top A, Ülkü S (2004) Silver, zinc, and copper exchange in a Naclinoptilolite and resulting effect on antibacterial activity. Appl Clay Sci 27:13-19

26. Chang EL, Simmers C, Knight DA (2010) Cobalt complexes as antiviral and antibacterial agents. Pharmaceuticals 3:1711-1728

27. Wheatley PS, Butler AR, Crane MS, Fox S, Xiao B, Rossi AG, Megson IL, Morris RE (2006) NO-releasing zeolites and their antithrombotic properties. J Am Chem Soc 128:502-509

28. Peppas NA, Bures P, Leobandung W, Ichikawa H (2000) Hydrogels in pharmaceutical formulations. Eur J Pharm Biopharm 50:27-46

29. Winter GD (1962) Formation of the scab and the rate of epithelialization of superficial wounds in the skin of the young domestic pig. Nature 193:293-294

30. Ratner BD, Hoffman AS (1976) Synthetic hydrogels for biomedical applications. In: Andrade JD (ed) Hydrogels for medical and related applications, ACS symposium series. American Chemical Society, Washington, pp 1-36

31. Hoffman AS (2002) Hydrogels for biomedical applications. Adv Drug Deliv Rev 54:3-12

32. Hickey AS, Peppas NA (1997) Solute diffusion in poly(vinyl alcohol)/poly(acrylic acid) composite films using freezing/thawing techniques. Polymer 38:5931-5936

33. Hennink WE, van Nostrum CF (2002) Novel crosslinking methods to design hydrogels. Adv Drug Deliv Rev 54:13-36

34. Peppas NA (1975) Turbidimetric studies of aqueous poly(vinyl alcohol) solutions. Macromol Chem Phys 176:3433-3440

35. Peppas NA, Merrill EW (1976) Differential scanning calorimetry of crystallized PVA hydrogels. J Appl Polym Sci 20:1457-1465

36. Peppas NA, Stauffer SR (1991) Reinforced uncrosslinked poly(vinyl alcohol) gels produced by cyclic freezing-thawing processes: a short review. J Control Release 16:305-310
37. Stauffer SR, Peppas NA (1992) Poly(vinyl alcohol) hydrogels prepared by freezing thawing cyclic processing. Polymer 33:3932-3936

38. Peppas NA, Scott JE (1992) Controlled release from poly(vinyl alcohol) gels prepared by freezing-thawing processes. J Control Release 18:95-100

39. Hassan CM, Peppas NA (2000) Structure and applications of poly(vinyl alcohol) hydrogels produced by conventional crosslinking or by freezing/thawing methods. J Adv Polym Sci 153:37-65

40. Hassan CM, Peppas NA (2000) Structure and morphology of freeze/thawed PVA hydrogels. Macromolecules 33:2472-2479

41. Peng Z, Kong LX (2007) A thermal degradation mechanism of polyvinyl alcohol/silica nanocomposites. Polym Degrad Stab 92:1061-1071

42. Chung YS, Kang SI, Kwon OW, Lee SG, Lee YR, Min BG, Han SS, Noh SH, Lyoo WS (2007) Preparation of hydroxyapatite/poly(vinyl alcohol) composite film. J Appl Polym Sci 104:3240-3244

43. Jia J, Duan YY, Wang SH, Zhang F, Wang ZY (2007) Preparation and characterization of antibacterial silver-containing nanofibers for wound dressing applications. J US China Med Sci 4:52-54

44. Li J, Suo J, Deng R (2010) Structure, mechanical, and swelling behaviors of poly(vinyl alcohol)/SiO${ }_{2}$ hybrid membranes. J Reinf Plast Compos 29:618-629

45. Pan Y (2010) Swelling properties of nano-hydroxyapatite reinforced poly(vinyl alcohol) gel biocomposites. Micro Nano Lett 5:237-240

46. Kokabi M, Sirousazar M, Hassan ZM (2007) PVA-clay nanocomposite hydrogels for wound dressing. Euro Polym J 43:773-781

47. Li M, Lu S, Wu Z, Tan K, Minoura N, Kuga S (2002) Structure and properties of silk fibroin-poly(vinyl alcohol) gel. Int J Biol Macromol 30:89-94

48. Hong PD, Chen JH, Wu HL (1998) Solvent effect on structural change of poly(vinyl alcohol) physical gels. J Appl Polym Sci 69:2477-2486

49. Qian XF, Yin J, Yang YF, Lu QH, Zhu ZK, Lu J (2001) Polymerinorganic nanocomposites prepared by hydrothermal method: preparation and characterization of PVA-transition-metal sulphides. J Appl Polym Sci 82:2744-2749

50. Sun H, Lu L, Peng F, Wu H (2006) Pervaporation of benzene/ cyclohexane mixtures through CMS-filled poly(vinyl alcohol) membranes. Sep Purif Technol 52:203-208

51. Zidan $\mathrm{HM}$ (2003) Structural properties of $\mathrm{CrF}_{3}-$ and $\mathrm{MnCl}_{2}$-filled poly(vinyl alcohol) films. J Appl Polym Sci 88:1115-1120

52. Lue SJ, Chen JY, Yang JM (2008) Crystallinity and stability of poly(vinyl alcohol)-fumed silica mixed matrix membrane. J Macromol Sci B 47:39-51

53. Sarsfield BA, Davidovich M, Desikan S, Fakes M, Futernik S, Hilden JL, Tan JS, Yin S, Young G, Vakkalagadda B, Volk K (2006) Powder X-ray diffraction detection of crystalline phases in amorphous pharmaceuticals. JCPDS-International Centre for Diffraction Data. ISSN 1097-0002

54. Cullity BD (1978) Elements of X-ray diffraction, 2nd edn. Addison-Wesley, Massachusetts

55. Blanton TN, Barnes CL, Lelental M (1991) The effect of X-ray penetration depth on structural characterization of multiphase $\mathrm{Bi}$ $\mathrm{Sr}-\mathrm{Ca}-\mathrm{Cu}-\mathrm{O}$ thin films by $\mathrm{X}$-ray diffraction techniques. Physica $\mathrm{C}$ Supercond 173:152-158

56. Peppas NA, Hansen PJ (1982) Crystallization kinetics of poly(vinyl alcohol). J Appl Polym Sci 27:4787-4797

57. Crank J, Park GS (1968) Diffusion in polymers. Academic Press, New York

58. Swartz ML, Norman RD, Gilmore HW, Phillips RW (1957) Studies on syneresis and imbibition in reversible hydrocolloid. J Dent Res 36:472-478 
59. Kunitz M (1928) Syneresis and swelling of gelatin. J Gen Physiol 12:289-312

60. Pal K, Banthia AK, Majumdar DK (2007) Preparation and characterization of polyvinyl alcohol-gelatin hydrogel membranes for biomedical applications. AAPS Pharm Sci Tech 8:E1-E5

61. Takeshita H, Kanaya T, Nishida K, Kaji K (1999) Gelation process and phase separation of PVA solutions as studied by a light scattering technique. Macromolecules 32:7815-7819

62. Kim JO, Park JK, Kim JH, Jin SG, Yong CS, Li DX, Choi JY, Woo JS, Yoo BK, Lyoo WS, Kim JA, Choi HG (2008) Development of polyvinyl alcohol-sodium alginate gel-matrix-based wound dressing system containing nitrofurazone. Int J Pharm 359:79-86

63. Blum P (1997) Physical properties handbook: a guide to the shipboard measurement of physical properties of deep-sea cores by the ocean drilling program. Texas A\&M University, Texas
64. Choi YS, Hong SR, Lee YM, Song KW, Park MH, Nam YS (1999) Study on gelatin-containing artificial skin. Part I. Preparation and characteristics of novel gelatin-alginate sponge. Biomaterials 20:409-417

65. Callister WD Jr (2003) Materials science and engineering: an introduction, 6th edn. Wiley, New York

66. Ricciardi R, Auriemma F, Gaillet C, De Rosa C, Laupretre F (2004) Investigation of the crystallinity of freeze/thaw poly(vinyl alcohol) hydrogels by different techniques. Macromolecules 37:9510-9516

67. Razzak MT, Darmawan D, Zainuddin Sukirno (2001) Irradiation of polyvinyl alcohol and polyvinyl pyrrolidone blended hydrogel for wound dressing. Radiat Phys Chem 62:107-113

68. Finch CA (1973) Polyvinyl alcohol. Wiley, Bristol 